\title{
In situ synthesis of cold-rollable aluminum-aluminum nitride composites via arc plasma-induced accelerated volume nitridation
}

\author{
J.I. Lee and E.S. Park ${ }^{\mathrm{a})}$ \\ Research Institute of Advanced Materials, Department of Materials Science and Engineering, Seoul National \\ University, Gwanak-gu, Seoul 08826, South Korea
}

(Received 7 June 2016; accepted 12 September 2016)

\begin{abstract}
Our study proposes in situ synthesis of cold-rollable aluminum nitride (AIN) reinforced aluminum matrix composites with attractive thermal properties via arc plasma-induced accelerated volume nitridation (APAVN). Within three minutes of repeated APAVN using commercial nitrogen gas, volume fraction of AIN increased up to $40 \mathrm{vol} \%$, which is the highest value ever reported by in situ nitridation of pure aluminum. The composites contained homogeneously dispersed AlN particulates with strong interfacial bonding and low interfacial thermal resistance, which resulted in unique combination of a relatively low coefficient of thermal expansion and high specific thermal conductivity. APAVN resulted from instantaneous chemisorption of dissociated nitrogen, enhanced diffusion of dissolved nitrogen, and improved wettability, which led to much more AlN formation, $\sim 2.94 \times 10^{-1} \mathrm{~g} /\left(\mathrm{min} \mathrm{cm}^{3}\right)$, which is about 400 times higher than that in the gas bubbling method. These results would ultimately give us a promising strategy for continuous production of in situ Al-AlN composites for heat sink applications through cost-effective processing.
\end{abstract}

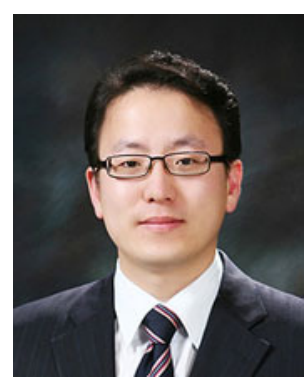

E.S. Park

Eun Soo Park received his Ph.D. in Metallurgical Engineering from Yonsei University, Korea, in 2005 and worked as a postdoctoral fellow in the Department of Applied Physics at Harvard University until 2008. Afterward he joined the Department of Materials Science and Engineering at Seoul National University in 2008 as an Assistant Professor, and was promoted to Associate Professor in 2012. Professor Park has been a visiting fellow at several universities and institutes, such as National Institute for Materials Science (2004, Japan), Tohoku University (2012, Japan), IFW Dresden (2005, 2014, Germany), MPIE Dusseldorf (2015, Germany), Indian Institute of Science Bangalore (2015, India), and, most recently, Lawrence Berkeley National Laboratory (2013-present, United States). He received the Young Leader Academic Award from the Korean Institute of Metals and Materials (2012) as well as an outstanding symposium paper award in 2007 and 2010 MRS fall meetings, and is selected to be a winner of 2016 TMS SMD Young Leaders Professional Development Award. He is on the editorial advisory board for Metals and Materials International. He is an expert on the physical metallurgy and mechanical behavior of bulk metallic glasses, high entropy alloys, and advanced engineering materials. His research interests are in the tailor-made materials design and microstructure-property relationships in metallic materials. He has authored more than 60 publications in respectable peer-reviewed journals including Progress in Materials Science, Acta Materialia, and Applied Physics Letters, several of which have garnered international recognition. In addition, he has also published more than 35 patents and 1 chapter of a technical book. According to Google Scholar, the total citation of his papers reaches about 2000, and his $\mathrm{H}$ index is 25 .

\section{INTRODUCTION}

As the thermal management industry has focused on finding new materials to improve heat dissipation that affects reliability and performance of electronic devices, $\mathrm{Al}$ matrix composites (AMCs) have attracted considerable interest due to their low density, high thermal conductivity (TC), and low coefficient of thermal expansion (CTE). ${ }^{1}$ However, AMCs manufactured by conventional ex situ processes are economically unfavorable due to expensive

Contributing Editor: Yang-T. Cheng

${ }^{a)}$ Address all correspondence to this author.

e-mail: espark@snu.ac.kr

DOI: $10.1557 / \mathrm{jmr} .2016 .422$ reinforcing materials and thermodynamic instability resulting from interfacial reaction between matrix and reinforcements. ${ }^{2}$ Thus, in situ fabrication of AMCs with a ceramic second phase such as $\mathrm{TiC}, \mathrm{Al}_{2} \mathrm{O}_{3}$, and $\mathrm{SiC}$ has been investigated for several decades and various processes like self-propagating high temperature synthesis, ${ }^{3}$ directed melt oxidation, ${ }^{4,5}$ or gas bubbling method ${ }^{2,6-10}$ have been developed as a feasible process depending on the formation of ceramic second phase.

Recently, aluminum nitride (AIN) has been considered as an attractive second phase in AMCs due to excellent TC and low CTE. ${ }^{10-14}$ Thus, a few scenarios have been proposed to fabricate in situ AMCs with AlN by nitridation of $\mathrm{Al}$ melt by gas-melt reaction. ${ }^{5,10}$ For 
example, as a directed melt nitridation process, ${ }^{5}$ molten $\mathrm{Al}-(\mathrm{Mg}, \mathrm{Si})$ alloys were heated above $1273 \mathrm{~K}$ and held for more than $12 \mathrm{~h}$ in nitrogen atmosphere, which promoted the formation of microporous $\mathrm{AlN}$ on the surface of molten alloy and outward growth of AIN by continuous wetting of the liquid alloy through the microchannel, resulting in the formation of AMCs with interconnected network of alloy and AIN. Although this process leads to the formation of AMCs with high volume fraction $\left(V_{\mathrm{p}}\right)$ of $\mathrm{AlN}$ above $50 \mathrm{vol} \%$, TC of $\mathrm{Al}$ matrix abruptly deteriorates with the addition of alloying elements, $\mathrm{Mg}$ and $\mathrm{Si}^{15}$ And in case of gas bubbling method, nitrogen-bearing gas was injected into $\mathrm{Al}$ melt at $1273-1473 \mathrm{~K}$ for $1-6 \mathrm{~h}$, but $V_{\mathrm{p}}$ of AlN obtained by mainly surface nitridation was less than $10 \mathrm{vol} \%{ }^{7}$ which is impractical to be applied for heat sinks. Thermal plasma evaporation process utilized high energy of plasma to synthesize AlN and $\mathrm{Al}-\mathrm{AlN}$ particles within several minutes. ${ }^{16}$ In the process, however, in situ formed particles were very small in size (50 $\mathrm{nm}$ in diameter) and the particles should be sintered with $\mathrm{Al}$ powders to produce bulky Al-AlN composites. ${ }^{11}$ In sum, although various approaches for fabricating in situ AMCs with $\mathrm{AlN}$ by nitridation of $\mathrm{Al}$ melt have been proposed, we are still far away from continuous production of in situ $\mathrm{Al}-$ AlN composites with attractive thermal properties through cost-effective processing.

In the present study, we report in situ formation of Al-AlN composites via arc plasma-induced accelerated volume nitridation (APAVN) of pure $\mathrm{Al}$ melt using $\mathrm{N}_{2}$ gas. In APAVN process, AlN second phase in $\mathrm{Al}$ melt was explosively produced by direct reaction between $\mathrm{Al}$ melt and dissociated nitrogen and arc plasma-induced ultra-high temperature. Al-AlN composite sheets were successfully fabricated by cold-rolling the as-melted Al-AlN ingots. The distinctive microstructure and thermal properties of the as-rolled composites were systematically characterized. In particular, the formation mechanism and formation kinetics of AlN in newly developed APAVN process were carefully discussed.

\section{EXPERIMENTAL}

Nitridation of $\mathrm{Al}$ (99.999\% purity) was performed by arc melting method ${ }^{17}$ with a constant arc voltage of $20 \mathrm{~V}$ and arc current of $150 \mathrm{~A}$. A button-shaped $\mathrm{Al}$ ingot $(6 \mathrm{~g}, 20 \mathrm{~mm}$, and $10 \mathrm{~mm}$ in weight, diameter, and height, respectively) was prepared by arc melting pure $\mathrm{Al}$ pieces under a Ti-gettered Ar atmosphere, and then the ingot, placed on water-cooled copper hearth, was arc melted under a Ti-gettered $\mathrm{Ar}-\mathrm{N}_{2}$ mixed atmosphere (2:1 ratio, $99.999 \%$ purity, total pressure of $60 \mathrm{kPa}$ ), which led to in situ formation of AlN in the Al melt. To minimize evaporation of $\mathrm{Al}$ and $\mathrm{AlN}$, arc melting was carefully performed for less than $60 \mathrm{~s}$ at a time. Otherwise, Al-AlN ingots become significantly porous and irregular in shape. ${ }^{18}$ The as-melted $\mathrm{Al}-\mathrm{AlN}$ ingots, which are similar in size to the pure $\mathrm{Al}$ ingot, were cold-rolled to a final thickness of $2 \mathrm{~mm}$ with a thickness reduction of $10 \%$ per pass for fragmentation and dispersion of $\mathrm{AlN}$ in $\mathrm{Al}$ matrix, resulting in the fabrication of a plate-type specimen with a width of about $20 \mathrm{~mm}$ and length of over $100 \mathrm{~mm}$.

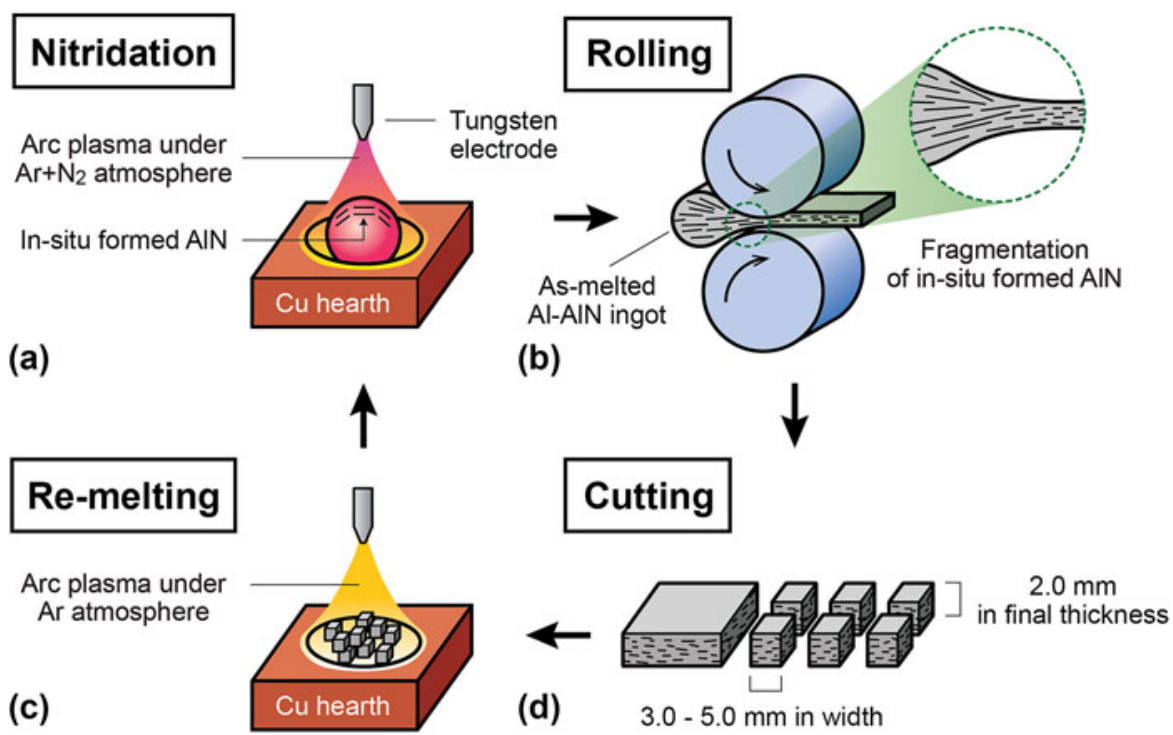

FIG. 1. Schematic diagram showing processing procedures for the fabrication of the Al-AlN composite sheets via repeated APAVN and coldrolling process. (a) Nitridation of a button-shaped pure Al ingot by arc melting under Ar mixed atmosphere. (b) Cold-rolling of an as-melted AlAlN ingot for fragmentation and dispersion of the in situ formed AlN, which led to fabrication of particulate composite sheets. (c) Cutting the asrolled composites into pieces for re-melting. (d) Re-melting the pieces of the as-rolled composites under an Ar atmosphere to prepare a buttonshaped Al-AlN ingot. 
To fabricate composites with higher fraction of AlN, the as-rolled composites were cut into pieces of about $4 \mathrm{~mm}$ in width (or length) and re-melted under a Ti-gettered Ar atmosphere to prepare button-shaped Al-AlN ingots, and then the ingots were melted again under a Ti-gettered $\mathrm{Ar}-\mathrm{N}_{2}$ mixed atmosphere for secondary nitridation. Sample size and dimensions can be increased by changing apparatus from laboratory scale (for producing a few grams of alloys) to industrial scale (for producing several tons of alloys). Figure 1 illustrates the sequence of APAVN process fabricating the Al-AlN composite sheets. The whole process in Fig. 1 was repeated up to three times (total nitridation time: $180 \mathrm{~s}$ ), which is scalable to commercial production.

Phase constitution was characterized by x-ray diffraction (XRD; New D8 Advance, Bruker Corporation, Karlsruhe, Germany) using monochromatic $\mathrm{Cu} \mathrm{K}_{\alpha}$ with a scanning rate of 4 degrees per minute. Microstructures were observed by optical microscope (OM; Eclipse LV 150, Nikon, Tokyo, Japan), scanning electron microscope (SEM; SU70, Hitachi Corp., Tokyo, Japan) and transmission electron microscope (TEM; JEM 2100F, JEOL Ltd., Tokyo, Japan). Thin foil specimens for TEM observation were prepared by Ar-ion milling using PIPS (Gatan Model 691, Gatan Inc., Pleasanton, California) at $2.7 \mathrm{keV}$ and $5 \mathrm{~mA}$ with liquid nitrogen cooling. $V_{\mathrm{p}}$ was evaluated from OM and SEM images using image analysis software. Thermal expansion behavior was characterized by thermo-mechanical analyzer (Q400, TA Instruments, New Castle, Delaware) at a heating rate of $5 \mathrm{~K} / \mathrm{min}$ with sample dimensions of $2 \times 2 \times 10 \mathrm{~mm}$. Thermal diffusivity was measured by laser flash analysis (LFA 447, NETZSCH Group, Selb, Germany) with sample dimensions of $12.7 \times 12.7 \times$ $2 \mathrm{~mm}$. Specific heat was measured using differential scanning calorimetry (DSC 8500, Perkin Elmer, Waltham, Massachusetts) and density was determined by Archimedes' method with an electrical balance (XS204, Mettler Toledo, Greifensee, Switzerland). TC was calculated as a product of thermal diffusivity, specific heat, and density of the composites.

\section{RESULTS}

\section{A. Microstructure analysis}

Figure 2 shows XRD patterns of the as-rolled Al-AlN composites with different nitridation times, which exhibits an Al-AlN dual phase constitution. $V_{\mathrm{p}}$ of AlN in composites increased as nitridation time increased, but was saturated around $40 \mathrm{vol} \%\left\{V_{\mathrm{p}}=40\left[1-\exp \left(-t_{\mathrm{N}} / 40\right)\right], t_{\mathrm{N}}\right.$ is nitridation time since molten $\mathrm{Al}$ with large fraction of AlN can be overheated by arc melting due to insufficient cooling, ${ }^{18}$ leading to evaporation of $\mathrm{Al}$ and decomposition of AlN $\left(T_{\mathrm{dec}}=2627 \mathrm{~K}\right.$ at $\left.60 \mathrm{kPa}\right)$. The composites

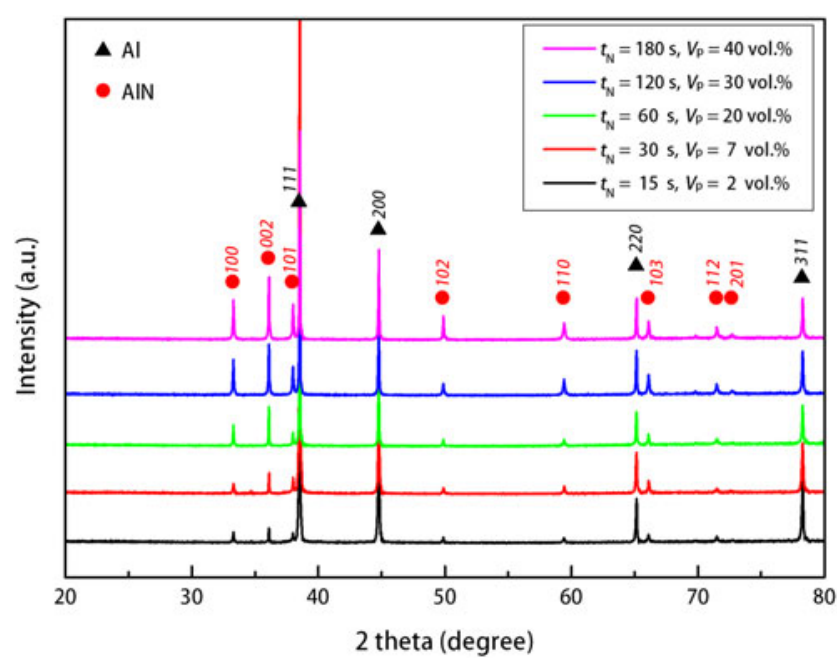

FIG. 2. XRD patterns of the as-rolled Al-AlN composites with different nitridation times $\left(t_{\mathrm{N}}=15,30,60,120\right.$, and $\left.180 \mathrm{~s}\right)$.

fabricated by $t_{\mathrm{N}}=180 \mathrm{~s}$ contained about $40 \mathrm{vol} \%$ of AlN, which is the highest value among in situ Al-AlN composites formed by nitridation of pure $\mathrm{Al}$ melt using $\mathrm{N}_{2}$ gas as a nitrogen source. ${ }^{7-10}$ At the maximum $V_{\mathrm{p}}$ of AlN, the specific weight gain normalized by $t_{\mathrm{N}}[=$ (weight of in situ formed AlN $) /\left(\right.$ total volume of Al melt $\left.\left.\times t_{\mathrm{N}}\right)\right]$ in APAVN process is $2.94 \times 10^{-1} \mathrm{~g} /\left(\operatorname{min~} \mathrm{cm}^{3}\right)$, which is about 400 times higher than that in the gas bubbling method $^{7}$ $\left[6.91 \times 10^{-4} \mathrm{~g} /\left(\mathrm{min} \mathrm{cm}^{3}\right)\right]$.

Figure 3(a) shows optical micrograph of the as-rolled Al-40 vol\% AlN composites, indicating a typical microstructure of particulate composites. The observed particle distribution analyzed by the quadrat method ${ }^{19}$ was similar to the Poisson distribution, which indicates homogeneous distribution of AlN particles in $\mathrm{Al}$ matrix. The average diameter of the AlN particles $\left(d_{\mathrm{p}}\right)$ was about $5 \mu \mathrm{m}$ [Fig. 3(b)]. The particles appeared approximately round-shaped, resulting from surface smoothing of AlN to reduce total free energy during the arc melting. Figure 3(c) shows a high-resolution TEM image of interface between $\mathrm{Al}$ matrix and AlN particles with their selected area electron diffraction patterns. The AlN particles were well-bonded to $\mathrm{Al}$ matrix without any contaminant or oxide layer since the in situ formation of AlN by arc melting method prevented surface oxidation and improved wettability between $\mathrm{Al}$ melt and AlN. In particular, Figs. 3(b) and 3(c) revealed that the AlN particles were completely wet by Al melt with arc plasma-induced ultra-high temperature over $2000 \mathrm{~K}$ (measured by pyrometer $^{18}$ or estimated by $\mathrm{Al}$ vapor pressure ${ }^{20}$ ) despite poor wettability of AlN by $\mathrm{Al}$ below $1573 \mathrm{~K}^{21}$

\section{B. Thermal properties}

Figure 4(a) compares CTE of the present Al-AlN composites with those of various reported $\mathrm{Al}-\mathrm{AlN}$ 

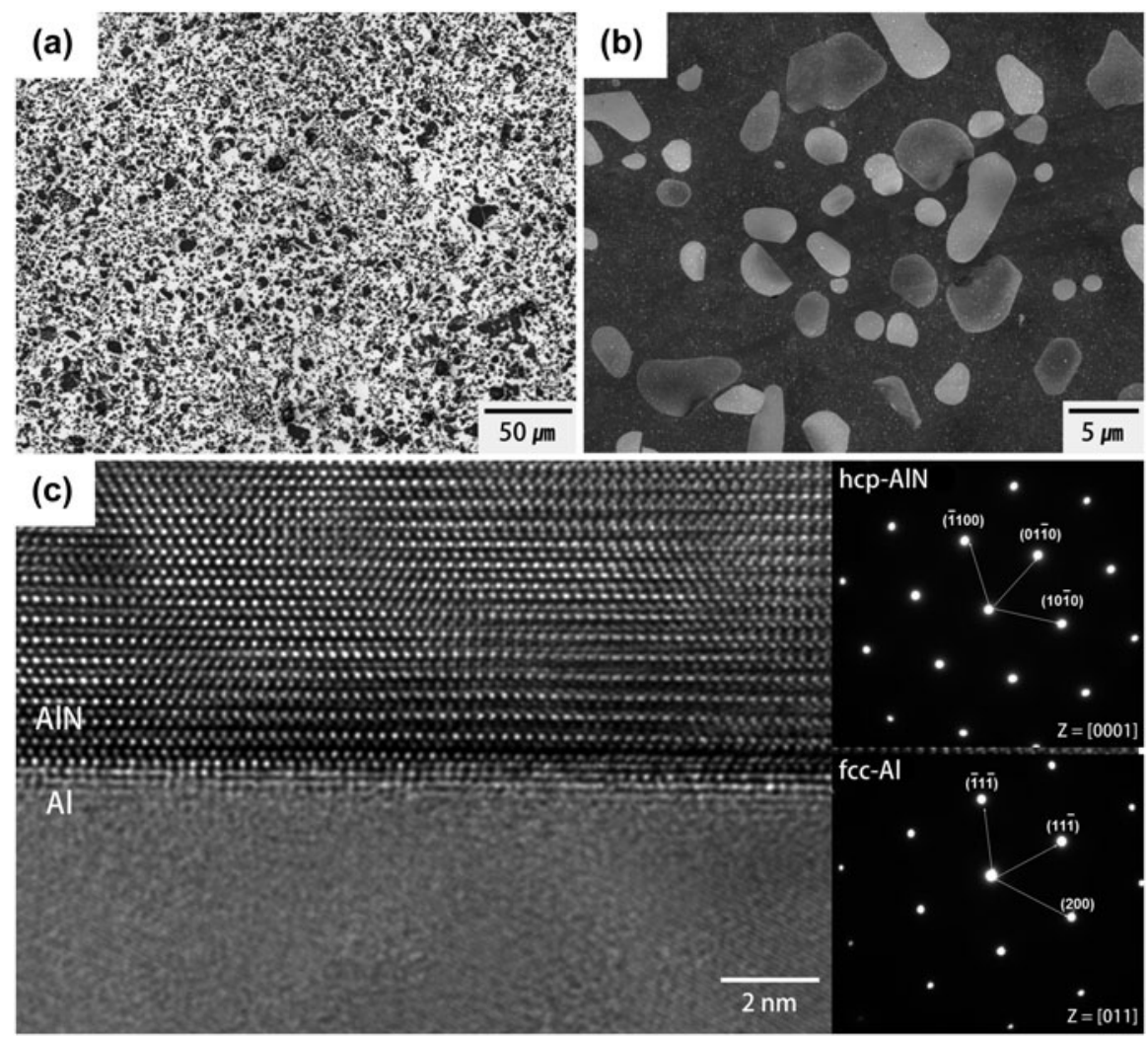

FIG. 3. (a) OM image, (b) SEM image, and (c) high-resolution TEM image with selected area diffraction patterns of the as-rolled Al-40 vol\% AlN composites.

composites and theoretically predicted values, ${ }^{11-14}$ indicating that CTE roughly decreases with increasing $V_{\mathrm{p}}$ of $\operatorname{AlN}\left(14.6 \pm 0.4 \times 10^{-6} \mathrm{~K}^{-1}\right.$ for 40 vol\% $\left.\mathrm{AlN}\right)$. Compared to Turner's model assuming equilibrium of internal stress between particles and matrix $\left[\alpha_{\mathrm{c}}=\left(\alpha_{\mathrm{m}} V_{\mathrm{m}} B_{\mathrm{m}}+\alpha_{\mathrm{p}} V_{\mathrm{p}} B_{\mathrm{p}}\right) /\left(V_{\mathrm{m}} B_{\mathrm{m}}+V_{\mathrm{p}} B_{\mathrm{p}}\right)\right]$, CTE of the present composites was well matched with Kerner's model assuming volumetric expansion of a spherical particle wet by matrix $;^{22}$

$$
\begin{aligned}
\alpha_{\mathrm{c}}=\alpha_{\mathrm{m}} & V_{\mathrm{m}}+\alpha_{\mathrm{p}} V_{\mathrm{p}}+V_{\mathrm{p}} V_{\mathrm{m}}\left(\alpha_{\mathrm{p}}-\alpha_{\mathrm{m}}\right) \\
& \times \frac{B_{\mathrm{p}}-B_{\mathrm{m}}}{V_{\mathrm{m}} B_{\mathrm{m}}+V_{\mathrm{p}} B_{\mathrm{p}}+3 B_{\mathrm{p}} B_{\mathrm{m}} / 4 G_{\mathrm{m}}},
\end{aligned}
$$

where $\alpha, V, \mathrm{~B}$, and $\mathrm{G}$ represent CTE $\left(23.6 \times 10^{-6} \mathrm{~K}^{-1}\right.$ for $\mathrm{Al}$ and $4.0 \times 10^{-6} \mathrm{~K}^{-1}$ for $\mathrm{AlN}$ ), volume fraction, bulk modulus (75.2 GPa for $\mathrm{Al}$ and $202 \mathrm{GPa}$ for $\mathrm{AlN}$ ), and shear modulus $(26.2 \mathrm{GPa}$ for $\mathrm{Al}$ and $126 \mathrm{GPa}$ for $\mathrm{AlN}$ ), respectively, and subscripts $\mathrm{c}, \mathrm{m}$, and $\mathrm{p}$ refer to composites, matrix, and particles, respectively. The correspondence between CTE of the present composites and Kerner's model indicates that the AlN particles introduced a constraint on the thermal expansion of the $\mathrm{Al}$ matrix, ${ }^{23}$ resulting from their strong interfacial cohesion that was shown by microstructures above [Figs. 3(b) and 3(c)].
Figure 4(b) shows the correlation between TC and interfacial thermal resistance ${ }^{24}$ (ITR) in the present $\mathrm{Al}-\mathrm{AlN}$ composites and various ex situ AMCs ( $V_{\mathrm{p}}$ of second phase in the composites is marked with number). ${ }^{11-13,25,26} \mathrm{TC}$ of the as-rolled Al-AlN composites was $194 \pm 4 \mathrm{~W} /(\mathrm{m} \mathrm{K})$, $178 \pm 4 \mathrm{~W} /(\mathrm{m} \mathrm{K})$, and $163 \pm 5 \mathrm{~W} /(\mathrm{m} \mathrm{K})$ for the samples with $20 \mathrm{vol} \%, 30 \mathrm{vol} \%$, and $40 \mathrm{vol} \%$ of AlN, respectively. The decrease in TC with increasing $V_{\mathrm{p}}$ of AlN can be explained by $\mathrm{H}-\mathrm{J}$ model, ${ }^{24}$ which describes effective $\mathrm{TC}$ of particulate composites as follows:

$$
K_{\mathrm{c}}=K_{\mathrm{m}} \frac{\left[2\left(\frac{K_{\mathrm{p}}}{K_{\mathrm{m}}}-\frac{K_{\mathrm{p}}}{r_{\mathrm{p}} h}-1\right) V_{\mathrm{p}}+\frac{K_{\mathrm{p}}}{K_{\mathrm{m}}}+\frac{K_{\mathrm{p}}}{r_{\mathrm{p}} h}+2\right]}{\left[\left(1-\frac{K_{\mathrm{p}}}{K_{\mathrm{m}}}+\frac{K_{\mathrm{p}}}{r_{\mathrm{p}}}\right) V_{\mathrm{p}}+\frac{K_{\mathrm{p}}}{K_{\mathrm{m}}}+\frac{K_{\mathrm{p}}}{r_{\mathrm{p}} h}+2\right]}
$$

where $K, r$, and $h$ represent TC, radius of particles, and reciprocal of ITR. TC of composites decreases with increasing $V_{\mathrm{p}}$ and decreasing size of particles due to the increase in total interfacial area that acts as a barrier to thermal conduction. In particular, it should be mentioned that in situ AMCs with AIN nanoparticles showed invalid ITR due to poor interface stability by oxide layer. Thus, it is expected that the present composites $\left(d_{\mathrm{p}}: 5 \mu \mathrm{m}\right)$ exhibit higher TC than AMCs reinforced with in situ formed AIN $\left(d_{\mathrm{p}}: 50 \mathrm{~nm}\right)$ fabricated by arc plasma evaporation and hot-pressing. ${ }^{11}$ ITR of composites is affected by interfacial 


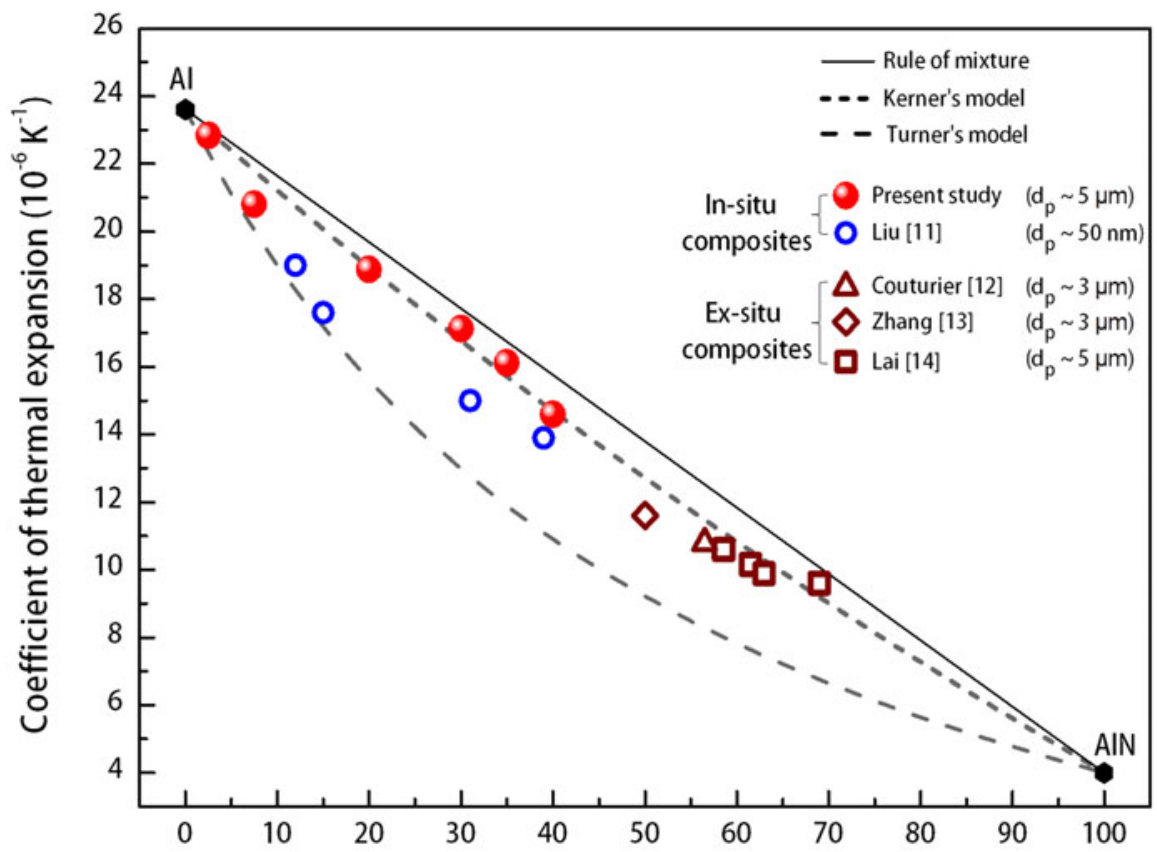

(a)

Volume fraction of AIN particles, $V_{p}($ vol.\%)

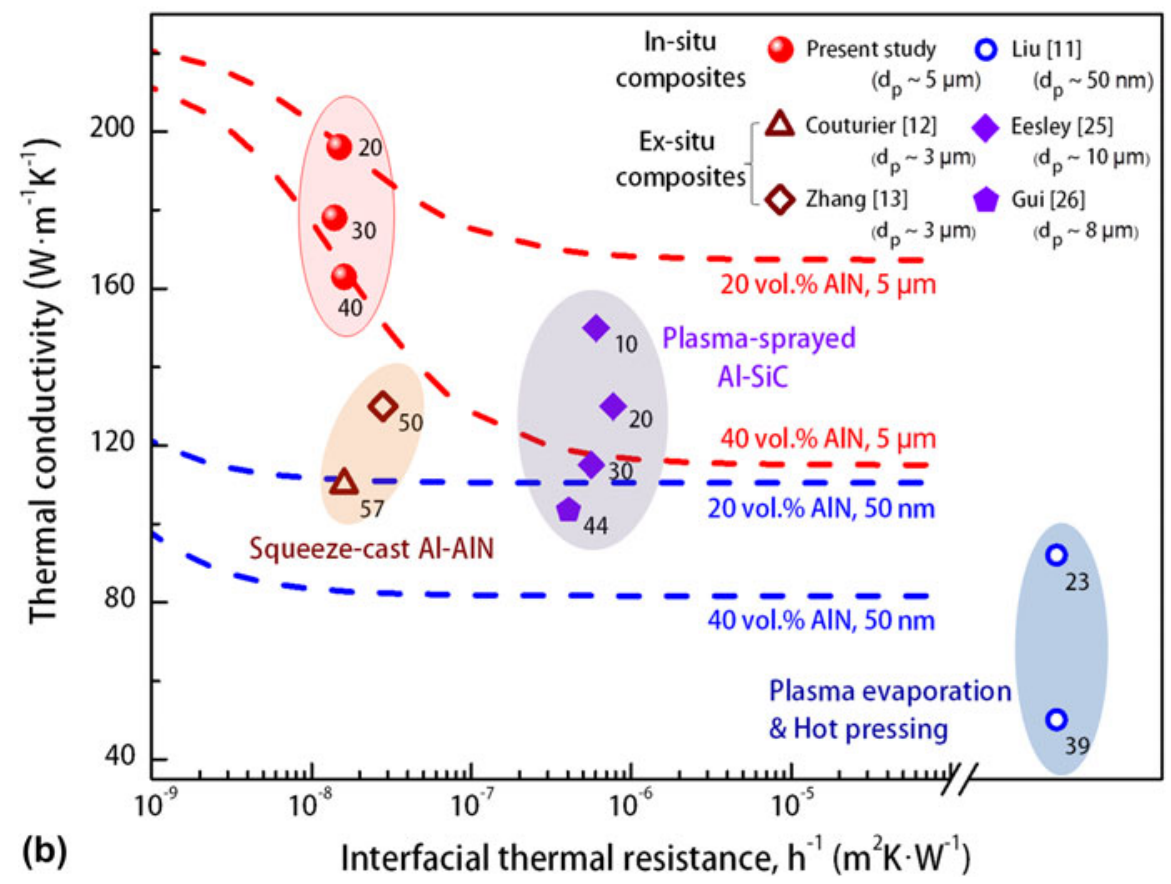

FIG. 4. (a) CTE of the present Al-AlN composites compared with that of various reported Al-AlN composites and theoretically predicted values. ${ }^{11-14}$ (b) Correlation between TC and ITR in the composites and various ex situ AMCs ( $V_{\mathrm{p}}$ of second phase is marked with number) ${ }^{11-13,25,26}$ Note that in situ AMCs with AlN nanoparticles showed invalid ITR due to their large oxygen contents and poor interface stability. ${ }^{11}$

adherence that can be degraded by the formation of an interfacial gap or a compound layer. Considering that $r_{\mathrm{p}}$, $K_{\mathrm{m}}$, and $K_{\mathrm{p}}$ in Eq. (2) are $2.5 \mu \mathrm{m}, 230 \mathrm{~W} /(\mathrm{m} \mathrm{K})$, and $200 \mathrm{~W} /(\mathrm{m} \mathrm{K})$, respectively, ITR of the present composites was calculated as $1.5 \pm 0.3 \times 10^{-8} \mathrm{~m}^{2} \mathrm{~K} / \mathrm{W}$ that is similar to that of AMCs produced by pressure-assisted infiltration ${ }^{12}$ or squeeze casting, ${ }^{13}$ and that is about ten times lower than that of plasma-sprayed AMCs, which exhibited poor interfacial bonding such as interfacial gaps or sprayed layerlayer boundaries. ${ }^{25,26}$ The low ITR of the present composites was attributed to strong interfacial bonding between $\mathrm{Al}$ and $\mathrm{AlN}$ without any interfacial compound layer. 


\section{DISCUSSION}

Our results demonstrate the feasibility of in situ forming Al-AlN composites by APAVN through arc melting of pure $\mathrm{Al}$ with $\mathrm{N}_{2}$ gas. Formation of $\mathrm{AlN}(\mathrm{Al}+\mathrm{N}=\mathrm{AlN}$, $\Delta H=-322 \mathrm{~kJ} / \mathrm{mol}$ ) is thermodynamically favorable, but oxygen content in $\mathrm{N}_{2}$ gas should be carefully controlled to reduce deleterious effects of oxygen on the nitridation of $\mathrm{Al}^{2}$ The addition of $\mathrm{Mg}$ in $\mathrm{Al}$ alloys is effective to initiate nitridation of $\mathrm{Al}$ melt since $\mathrm{Mg}$ acts as an oxygen getter ${ }^{5}$ and a catalysis by forming intermediate $\mathrm{Mg}_{3} \mathrm{~N}_{2}$ phase that reacts with $\mathrm{Al}\left(2 \mathrm{Al}+\mathrm{Mg}_{3} \mathrm{~N}_{2} \rightarrow 2 \mathrm{AlN}+3 \mathrm{Mg}\right) .^{10}$ However, $\mathrm{TC}$ of $\mathrm{Al}$ matrix significantly deteriorates with the addition of $\mathrm{Mg},{ }^{15}$ which reduces applicability of AMCs to heat sink applications. In this study, Al-AlN composites with high $V_{\mathrm{p}}$ of AlN (up to $40 \mathrm{vol} \%$ ) were synthesized within $180 \mathrm{~s}$ by newly developed APAVN process of pure $\mathrm{Al}$ melt with commercial $\mathrm{N}_{2}$ gas. The formation mechanism and formation kinetics of AlN in APAVN process were carefully discussed and compared with the gas bubbling method where $\mathrm{N}_{2}$ gas is directly injected to $\mathrm{Al}$ melt and results in mainly surface nitridation.

\section{A. Evaluation of AIN formation mechanism in APAVN process}

Figure 5 graphically illustrates the detailed AlN formation mechanism in APAVN process. Nitrogen molecules $\left(\mathrm{N}_{2}\right)$ are dissociated into atomic nitrogen $(\mathrm{N})$

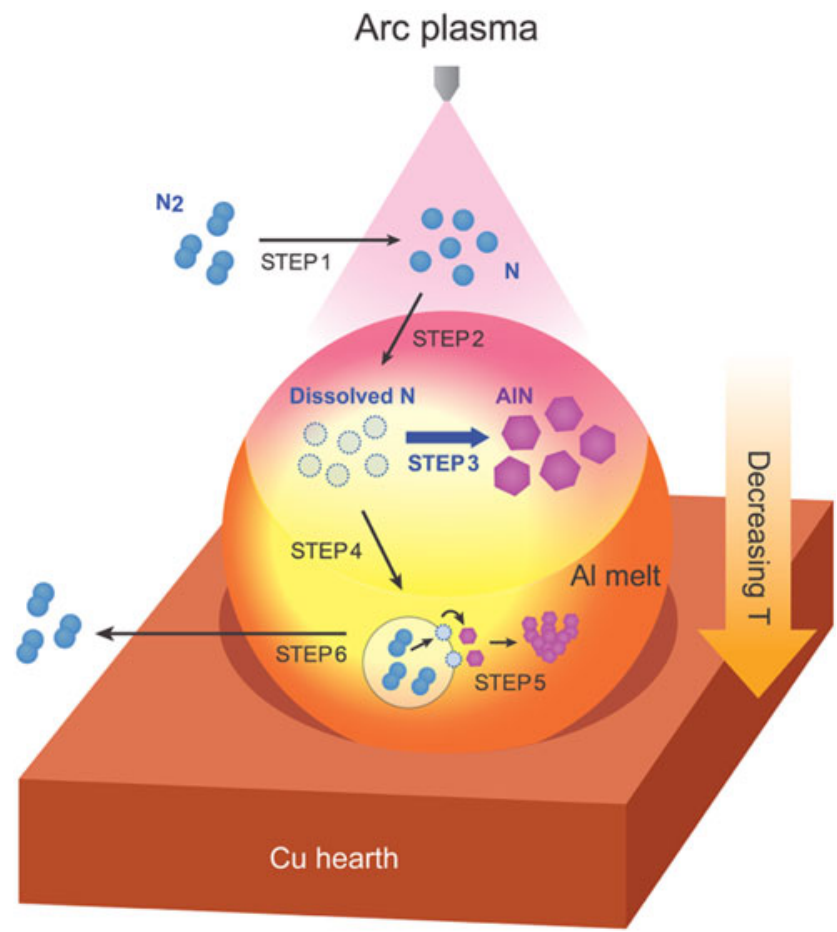

FIG. 5. Schematic diagram showing AIN formation mechanism in APAVN process. by arc plasma-induced ultra-high temperature (Step 1). ${ }^{27}$ The dissociated $\mathrm{N}$ is dissolved to $\mathrm{Al}$ melt through gas-melt interface subjected to elevated temperature over $2000 \mathrm{~K}^{18,20}$ (Step 2). It should be noted that dissolution of the dissociated $\mathrm{N}$ into the $\mathrm{Al}$ melt is instantaneous due to the absence of activation energy for chemisorption, ${ }^{28}$ while the chemisorption of $\mathrm{N}_{2}$ requires overcoming activation energy barrier $(308 \mathrm{~kJ} / \mathrm{mol})$ due to the transition from physisorbed state to chemisorbed state. ${ }^{7}$ Furthermore, solubility of $\mathrm{N}$ in $\mathrm{Al}$ at $2000 \mathrm{~K}$ was estimated to be about 0.3 at $\%,{ }^{29}$ indicating that dissolution of the dissociated $\mathrm{N}$ is thermodynamically favorable at the gas-melt interface. Thus, the arc melting method can be an effective route to dissolve significant amount of $\mathrm{N}$ into $\mathrm{Al}$ melt and improve wettability, and AlN can be explosively in situ formed at the gas-melt interface and under the interface (Step 3), which leads to volume nitridation of $\mathrm{Al}$. Due to strong temperature gradient of the $\mathrm{Al}$ melt cooled by copper hearth, $\mathrm{N}_{2}$ bubbles are recombined at the bottom of the $\mathrm{Al}$ melt (Step 4), ${ }^{27}$ resulting in the formation of AlN particles during the rise of the bubbles in the $\mathrm{Al}$ melt with high content of the dissolved N (Step 5). ${ }^{8}$ The in situ formed AlN in Step 5 exhibited a different morphology compared to the AlN formed in Step 3, which will be discussed in Fig. 6. The bubbles escape from the Al melt due to buoyancy force and $\mathrm{N}_{2}$ molecules are released from the bubbles (Step 6).

Figure 6(a) shows schematic diagrams for two representative AlN morphologies formed by APAVN process (Step 3 and Step 5 in Fig. 5). First, AlN synthesized in Step 3 exhibited the form of plates with large area [Fig. 6(b)], which is a typical morphology of AlN formed at the surface of $\mathrm{Al}$ melt. Thickness of the plates was close to $5 \mu \mathrm{m}$ that is larger than that of AlN layer $\left(350 \mathrm{~nm}\right.$ ) formed on surface of liquid $\mathrm{Al}$ under $\mathrm{N}_{2}$ atmosphere at $973 \mathrm{~K},{ }^{30}$ indicating that the formation of thicker AlN plates with large area $(>100 \mu \mathrm{m}$ in diameter) was favorable in APAVN process. During arc melting, the in situ formed plates sank to the bottom of the Al melt due to the difference in their density $\left(2.7 \mathrm{~g} / \mathrm{cm}^{3}\right.$ for $\mathrm{Al}$ and $3.3 \mathrm{~g} / \mathrm{cm}^{3}$ for $\left.\mathrm{AlN}\right)$, and improved wettability between AlN and Al melt by arc plasmainduced ultra-high temperature that resulted in continuous wetting of the Al melt through surface of the AlN plates. Consequently, new plates were synthesized at the gas-melt interface, which led to stacking of the AlN plates in the whole Al melt. Simultaneously, AlN rods appeared to grow from the plates toward the gas-melt interface [Fig. 6(b)]. The unidimensional growth of AlN can be explained by vapor-liquid-solid growth mechanism ${ }^{31}$ in which supersaturation of liquid $\mathrm{Al}$ by $\mathrm{N}$ promotes anisotropic crystal growth of AlN from the plates. ${ }^{32}$ The supersaturation may result from delayed convection of the $\mathrm{Al}$ melt between the pre-stacked plates where the 

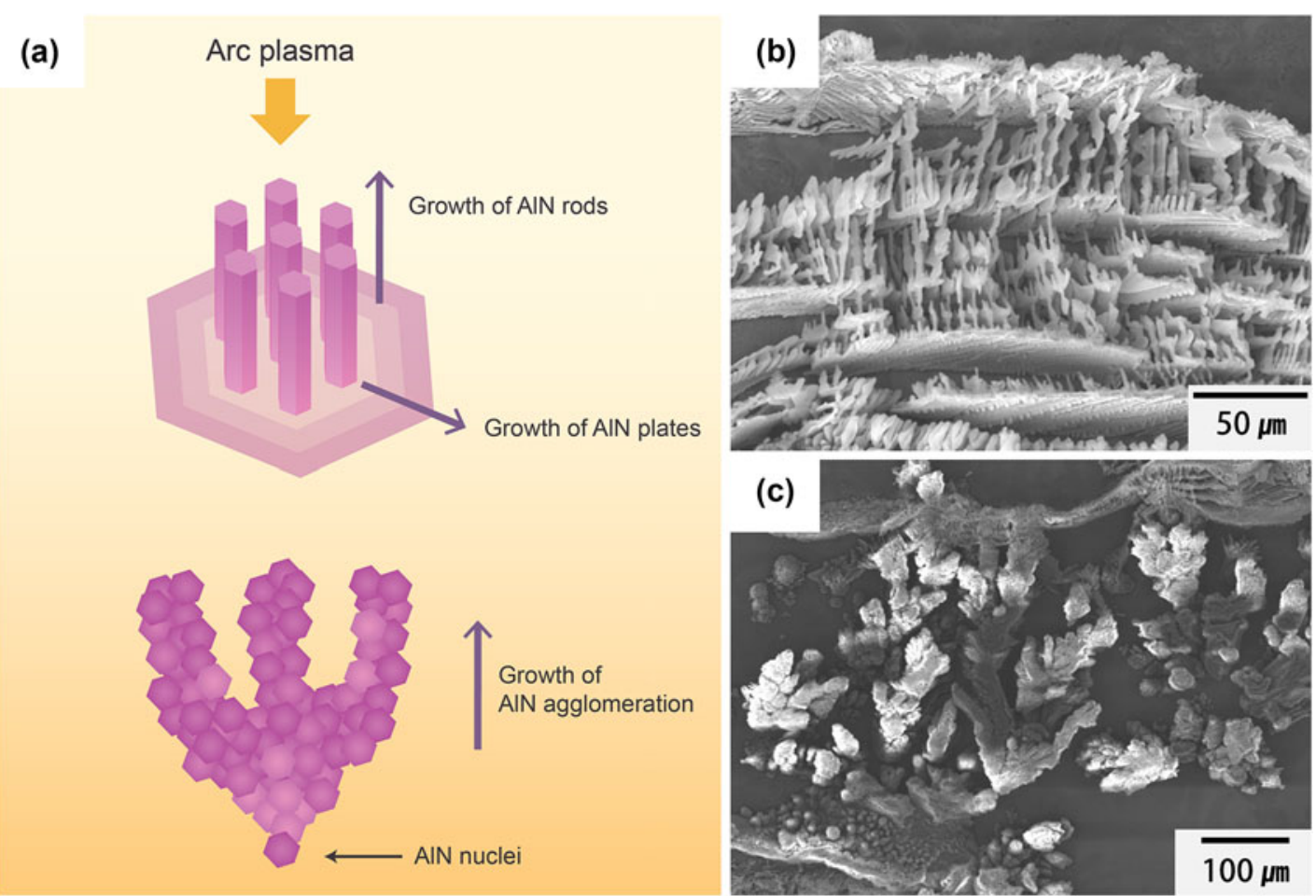

FIG. 6. (a) Schematic diagram showing two representative AlN morphologies formed in an as-melted Al-AlN ingot via APAVN process. SEM images of (b) plate-shaped AlN with rods (upper part of the ingot) and (c) agglomeration of AlN particles (bottom part of the ingot) after nitridation time of $60 \mathrm{~s}$ in APAVN process.

dissolved $\mathrm{N}$ was locally enriched. Second, AlN synthesized in Step 5 exhibited the form of agglomerates of small AlN particles $\left(d_{\mathrm{p}}<2.5 \mu \mathrm{m}\right)$ [Fig. 6(c)]. Growth of the agglomerates was initiated from AlN nuclei, formed at the interface between $\mathrm{Al}$ melt and $\mathrm{N}_{2}$ bubble, ${ }^{10}$ toward the gas-melt interface due to the gradient of dissolved $\mathrm{N}$. The appearance of the agglomerates was similar to that of the surface of nitrided $\mathrm{Al}$ powder at the temperature below $1273 \mathrm{~K},{ }^{30,33}$ indicating limited growth of AlN crystals due to the relatively low temperature.

\section{B. Comparison of AIN formation rate between APAVN process and gas bubbling method}

Since the AlN formation rate $\left(\theta_{\mathrm{AlN}}\right)$ in the gas bubbling method was evaluated by considering concentration and diffusion of the dissolved $\mathrm{N}$ in $\mathrm{Al}$ melt, ${ }^{6,8}$ the predominance of $\mathrm{N}$ diffusion in this study was investigated by determining concentration profiles. The diffusion of $\mathrm{N}$ in $\mathrm{Al}$ melt was estimated by Fick's second law as follows:

$$
\frac{\partial C_{\mathrm{N}}}{\partial t}=D_{\mathrm{N}} \frac{\partial^{2} C_{\mathrm{N}}}{\partial x^{2}}
$$

where $C$ is concentration (in moles per liter), and $D_{\mathrm{N}}$ is diffusivity of $\mathrm{N}$ in $\mathrm{Al}$ melt as follows:

$$
D_{\mathrm{N}}=D_{0} \exp \left(-\frac{E_{\mathrm{N}}}{R T_{1}}\right)
$$

where $D_{0}$ is pre-exponential constant, $3.75 \times 10^{-7} \mathrm{~m}^{2} / \mathrm{s}$, and $E_{\mathrm{N}}$ is activation energy for $\mathrm{N}$ diffusion, $26.47 \mathrm{~kJ} / \mathrm{mol}$. $R$ is gas constant and $T_{1}$ is temperature of $\mathrm{Al}$ melt. With boundary conditions (at $x=0, C_{\mathrm{N}}=C_{\mathrm{N}, i}$ and at $x=\infty$, $C_{\mathrm{N}}=0$ ), Eq. (3) yields the following solutions:

$$
C_{\mathrm{N}, x}=C_{\mathrm{N}, i}\left(1-\operatorname{erf}\left(\frac{x_{\mathrm{N}}}{2 \sqrt{D_{\mathrm{N}} t_{\mathrm{N}}}}\right)\right),
$$

where $x_{\mathrm{N}}$ and $t_{\mathrm{N}}$ are diffusion length and time of $\mathrm{N}$, respectively. $C_{\mathrm{N}, x}$ and $C_{\mathrm{N}, i}$ are concentration of $\mathrm{N}$ at the distance $x$ from the gas-melt interface and at the gas-melt interface, respectively. $C_{\mathrm{N}, i}$ was evaluated as follows:

$$
C_{\mathrm{N}, i}=k C_{\mathrm{N}, g}
$$

where $k$ and $C_{\mathrm{N}, g}$ are dimensionless Henry's law constant and concentration of nitrogen gas in chamber, respectively. $C_{\mathrm{N}, g}$ was evaluated as follows, assuming that the gas obeys ideal gas law $(P V=n R T)$ :

$$
C_{\mathrm{N}, g}=\frac{P_{\mathrm{N}}}{R T_{\mathrm{N}}},
$$


where $P_{\mathrm{N}}$ and $T_{\mathrm{N}}$ refer to partial pressure and temperature of nitrogen gas. Figure 7 shows the diffusion profiles of the dissociated $\mathrm{N}$ in $\mathrm{Al}$ melt for APAVN process, calculated using Eqs. (3)-(7) with an assumption that $D_{\mathrm{N}}$ is constant since AlN is dominantly formed at the gas-melt interface where $C_{\mathrm{N}, i}$ and $T_{1}$ are constants, which were compared against those of $\mathrm{N}_{2}$ gas for the gas bubbling method. ${ }^{7}$ Although $P_{\mathrm{N}}$ of APAVN process $(0.2 \mathrm{~atm})$ was lower than that of the gas bubbling method $(1.0 \mathrm{~atm})$, APAVN process exhibited higher $C_{\mathrm{N}, i}\left(9.22 \times 10^{-4} \mathrm{~mol} / \mathrm{L}\right)$ than the gas bubbling method $\left(1.65 \times 10^{-4} \mathrm{~mol} / \mathrm{L}\right)^{7}$ due to the difference in $k$ in Eq. (6). In APAVN process, the $k$ can be assumed as 1 since dissociated $\mathrm{N}$ by arc plasma is instantaneously dissolved into $\mathrm{Al}$ melt without overcoming activation energy (Step 2 in Fig. 5). In the gas bubbling method, the $k$ was estimated as $1.99 \times 10^{-2}$ at $1473 \mathrm{~K}$ that was derived from the solubility of $\mathrm{N}$ in $\mathrm{Al}^{34} \theta_{\mathrm{AlN}}$ in the gas bubbling method was calculated by the equation, $\theta_{\mathrm{AIN}}=a D_{\mathrm{N}}^{0.5} C_{\mathrm{N}, i}(a$ is constant $)$ since the formation of AlN occurs mainly at the gas-melt interface and $C_{\mathrm{N}}$ is much smaller than $C_{\mathrm{Al}}$ in $\mathrm{Al}$ melt (surface nitridation). ${ }^{6}$ Based on the same assumption, $\theta_{\mathrm{AIN}}$ in the APAVN process was calculated to be about ten times higher than that in the gas bubbling method since $T_{\mathrm{N}}$ was higher over $1000 \mathrm{~K}$, and $C_{\mathrm{N}, i}$ was about 5.6 times greater. However, it was insufficient to explain about 400 times higher specific weight gain normalized by $t_{\mathrm{N}}$ in the APAVN process compared to that in the gas bubbling method. Compared to the gas bubbling method, where $\mathrm{N}_{2}$ bubbles escape from $\mathrm{Al}$ melt within a few seconds, the dissociated $\mathrm{N}$ in the APAVN process is continuously supplied to $\mathrm{Al}$ melt during arc melting, resulting in volume nitridation as explained in Fig. 6(b). Therefore, the higher $V_{\mathrm{p}}$ of AlN in the APAVN process can be rationalized by unique volume nitridation due to increased $C_{\mathrm{N}, i}$ from the instantaneous chemisorption of the dissociated $\mathrm{N}$, increased $C_{\mathrm{N}, x}$ from the enhanced $\mathrm{N}$ diffusion in $\mathrm{Al}$ melt, and improved wettability between $\mathrm{AlN}$ and $\mathrm{Al}$ melt.

\section{Manipulation of thermal properties via APAVN process}

Figure 8 shows specific TC of the as-rolled Al-AlN composites via APAVN process compared with various pure metals, ceramics, and AMCs as a function of CTE. ${ }^{11-13,25,26}$ When it comes to materials choice for heat sink applications, the density is a major consideration. ${ }^{35}$ Late transition metals such as Mo and $\mathrm{W}$ are well known for their high TC with low CTE, but their high density limits their use. The as-rolled Al-AlN composites exhibit a unique combination of higher specific TC and lower CTE than in situ Al-AlN nanocomposites ${ }^{11}$ or plasma-sprayed AMCs ${ }^{25,26}$ which can be manipulated by controlling $V_{\mathrm{p}}$ as well as the size of AlN. Furthermore, ITR of Al-AlN interface, prepared by sputtering of $\mathrm{Al}$ on AlN single crystal in vacuum, was $4.3 \times 10^{-9} \mathrm{~m}^{2} \mathrm{~K} / \mathrm{W},{ }^{36}$ indicating that $\mathrm{TC}$ of the present composites can be further improved by optimizing processing parameters to reduce ITR. Consequently, the present $\mathrm{Al}-\mathrm{AlN}$ in situ composites formed by APAVN process exhibit an attractive combination of higher specific TC and lower CTE as well as reduced materials cost; therefore, it seems promising for heat sink applications, especially for portable electronic devices.

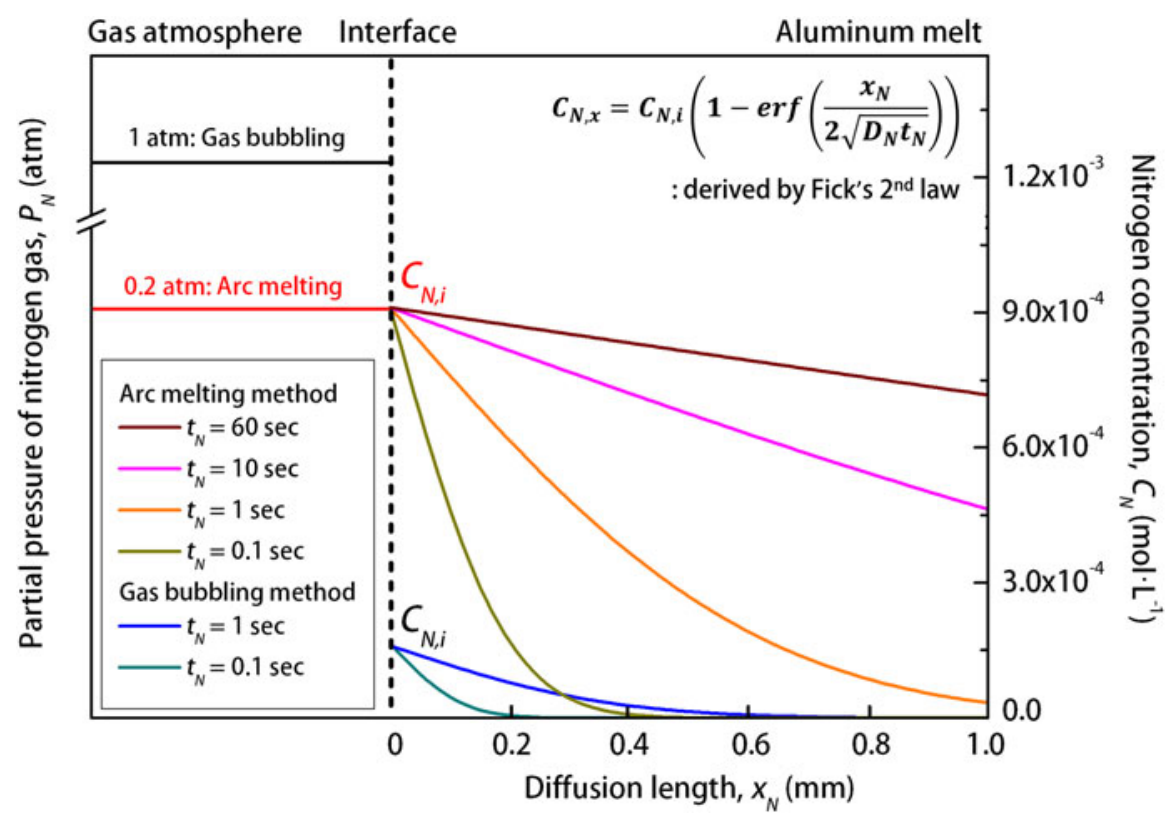

FIG. 7. Diffusion profiles of $\mathrm{N}$ in $\mathrm{Al}$ melt for APAVN process compared with those for gas bubbling method. ${ }^{7}$ 


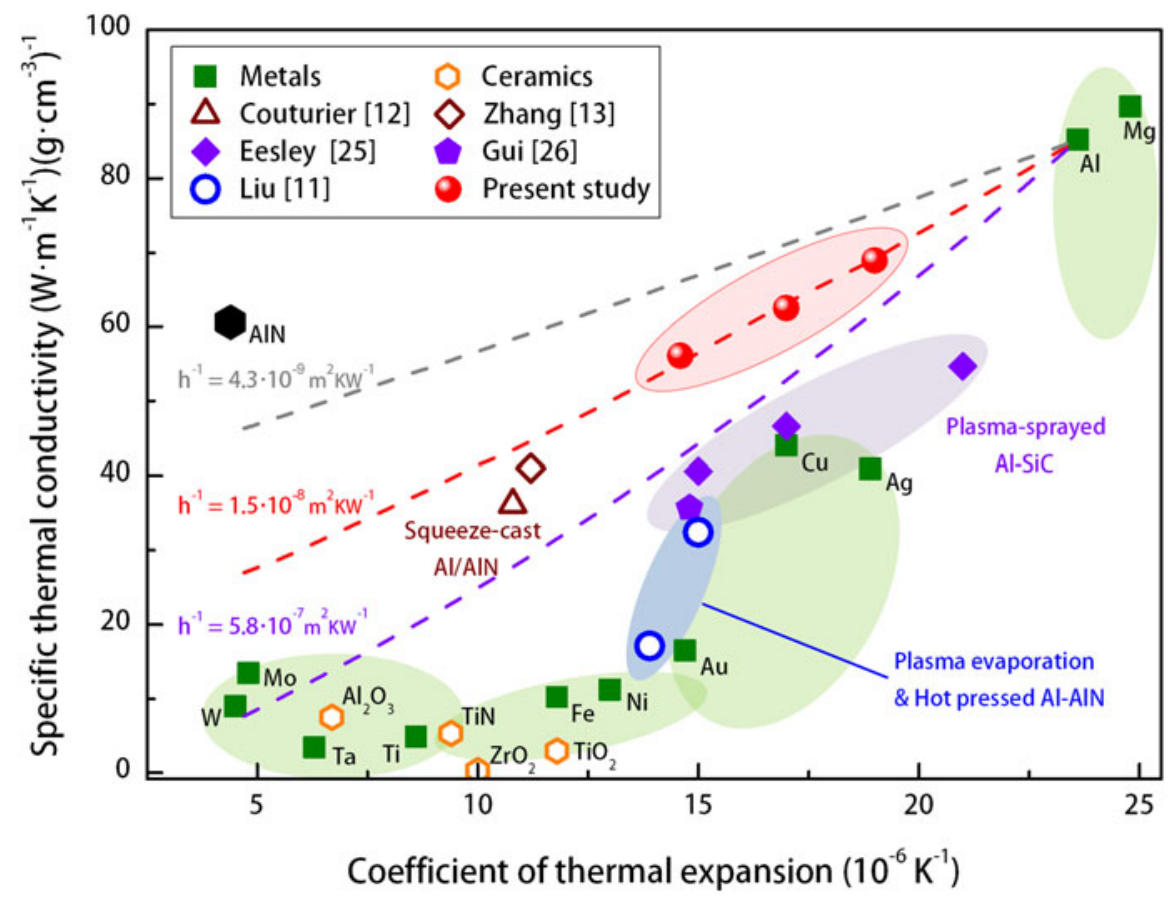

FIG. 8. Correlation between specific TC and CTE of the Al-AlN composites fabricated via APAVN process in relation to various metals, ceramics, and AMCs. ${ }^{1-13,25,26}$

\section{CONCLUSIONS}

The present study shows the in situ synthesis of Al-AlN composites with attractive thermal properties via APAVN process. APAVN resulted from the instantaneous chemisorption of the dissociated $\mathrm{N}$, enhanced diffusion of the dissolved $\mathrm{N}$ in $\mathrm{Al}$ melt and improved wettability between AlN and Al melt, which led to higher AlN formation of $\sim 2.94 \times 10^{-1} \mathrm{~g} /\left(\mathrm{min} \mathrm{cm}^{3}\right)$ that is about 400 times higher than that in the gas bubbling method $\left[6.91 \times 10^{-4} \mathrm{~g} /\left(\mathrm{min} \mathrm{cm}^{3}\right)\right]$. Thus, within a few minutes of repeated APAVN under commercial $\mathrm{N}_{2}$ gas, volume fraction of AlN increased up to $40 \mathrm{vol} \%$, which is the highest value ever reported by in situ nitridation of pure $\mathrm{Al}$ melt using high-purity $\mathrm{N}_{2}$ gas. The composites contained homogeneously dispersed AIN particles with strong interfacial bonding and low ITR, which resulted in a unique combination of a relatively low CTE $\left(14.6 \pm 0.4 \times 10^{-6} \mathrm{~K}^{-1}\right)$ and high TC $[163 \pm 5 \mathrm{~W} /(\mathrm{m} \mathrm{K})]$. Our current finding gives us a guideline on how to design a simple process for continuous production of in situ Al-AlN composite sheets with tailor-made thermal properties for heat sink applications.

\section{ACKNOWLEDGMENTS}

The author's work in this area was supported by the National Research Foundation of Korea (NRF) grant funded by the Korean government (Ministry of Science, ICT and Future Planning) (No. 2014K1A3A1A20034841
\& 2014M3C1A8053728). One of the authors (E.S. Park) was also benefited from the Center for Iron and Steel Research at Seoul National University.

\section{REFERENCES}

1. C. Zweben: Advances in composite materials for thermal management in electronic packaging. JOM 50, 6 (1998).

2. Q. Zheng, B. Wu, and R.G. Reddy: In situ processing of Al alloy composites. Adv. Eng. Mater. 5, 3 (2003).

3. P. Li, E. Kandalova, V. Nikitin, A. Makarenko, A. Luts, and Z. Yanfei: Preparation of Al-TiC composites by self-propagating high-temperature synthesis. Scr. Mater. 49, 7 (2003).

4. M.S. Newkirk, A. Urquhart, H. Zwicker, and E. Breval: Formation of Lanxide ceramic composite materials. J. Mater. Res. 1, 1 (1986).

5. H. Scholz and P. Greil: Nitridation reactions of molten $\mathrm{Al}-(\mathrm{Mg}, \mathrm{Si})$ alloys. J. Mater. Sci. 26, 3 (1991).

6. Q. Zheng and R.G. Reddy: Kinetics of in situ formation of AlN in Al alloy melts by bubbling ammonia gas. Metall. Mater. Trans. B 34, 6 (2003).

7. Q. Zheng and R. Reddy: Mechanism of in situ formation of AlN in Al melt using nitrogen gas. J. Mater. Sci. 39, 1 (2004).

8. C. Borgonovo, D. Apelian, and M. Makhlouf: Aluminum nanocomposites for elevated temperature applications. JOM 63, 2 (2011).

9. S.S. Kumari, U. Pillai, and B. Pai: Synthesis and characterization of in situ Al-AlN composite by nitrogen gas bubbling method. J. Alloys Compd. 509, 5 (2011).

10. Q. Hou, R. Mutharasan, and M. Koczak: Feasibility of aluminium nitride formation in aluminum alloys. Mater. Sci. Eng., A 195, 121 (1995).

11. Y.Q. Liu, H. Cong, and H. Cheng: Thermal properties of nanocrystalline Al composites reinforced by AlN nanoparticles. J. Mater. Res. 24, 1 (2009). 
12. R. Couturier, D. Ducret, P. Merle, J. Disson, and P. Joubert: Elaboration and characterization of a metal matrix composite: Al/AlN. J. Eur. Ceram. Soc. 17, 15 (1997).

13. Q. Zhang, G. Chen, G. Wu, Z. Xiu, and B. Luan: Property characteristics of a AlNp/Al composite fabricated by squeeze casting technology. Mater. Lett. 57, 8 (2003).

14. S-W. Lai and D. Chung: Superior high-temperature resistance of aluminium nitride particle-reinforced aluminium compared to silicon carbide or alumina particle-reinforced aluminium. J. Mater. Sci. 29, 23 (1994).

15. C.Y. Ho, M. Ackerman, K. Wu, S. Oh, and T. Havill: Thermal conductivity of ten selected binary alloy systems. J. Phys. Chem. Ref. Data 7, 3 (1978).

16. M. Koczak and M.K. Premkumar: Emerging technologies for the in situ production of MMCs. JOM 45, 1 (1993).

17. C. Suryanarayana and A. Inoue: Bulk Metallic Glasses (CRC Press, Boca Raton, 2011); p. 166.

18. K. Etemadi: Formation of aluminum nitrides in thermal plasmas. Plasma Chem. Plasma Proc. 11, 1 (1991).

19. P.A. Karnezis, G. Durrant, and B. Cantor: Characterization of reinforcement distribution in cast $\mathrm{Al}$-alloy/SiCp composites. Mater. Charact. 40, 2 (1998).

20. J.E. Hatch: Aluminum: Properties and Physical Metallurgy (ASM International, Materials Park, 1984); p. 15.

21. C. Toy and W. Scott: Wetting and spreading of molten aluminium against AlN surfaces. J. Mater. Sci. 32, 12 (1997).

22. Y. Nishida: Introduction to Metal Matrix Composites: Fabrication and Recycling (Springer Science \& Business Media, New York, 2013); p. 143.

23. K.K. Chawla: Metal Matrix Composites (Springer Science \& Business Media, New York, 2013); pp. 141-144.

24. D.P.H. Hasselman and L.F. Johnson: Effective thermal conductivity of composites with interfacial thermal barrier resistance. J. Compos. Mater. 21, 6 (1987).
25. G.L. Eesley, A. Elmoursi, and N. Patel: Thermal properties of kinetic spray Al-SiC metal-matrix composite. J. Mater. Res. 18, 4 (2003).

26. M. Gui, S.B. Kang, and K. Euh: Thermal conductivity of Al-SiCp composites by plasma spraying. Scr. Mater. 52, 1 (2005).

27. K. Tanaka, K. Ishizaki, S. Yumoto, T. Egashira, and M. Uda: Production of ultra-fine silicon powder by the arc plasma method. J. Mater. Sci. 22, 6 (1987).

28. J. Lennard-Jones: Processes of adsorption and diffusion on solid surfaces. Trans. Faraday Soc. 28, 333 (1932).

29. M. Boćkowski, M. Wroblewski, B. Łucznik, and I. Grzegory: Crystal growth of aluminum nitride under high pressure of nitrogen. Mater. Sci. Semicond. Process. 4, 6 (2001).

30. S-H. Kim, J-H. Noh, J-P. Ahn, J-C. Lee, H. Kwon, J. Lee, H.R. Yang, and K-B. Lee: Effects of surface oxide on the nitridation behavior of aluminum particles. Metall. Mater. Trans. A 46, 1 (2015).

31. R. Wagner and W. Ellis: Vapor-liquid-solid mechanism of single crystal growth. Appl. Phys. Lett. 4, 5 (1964).

32. C. Liu, Z. Hu, Q. Wu, X. Wang, Y. Chen, H. Sang, J. Zhu, S. Deng, and N. Xu: Vapor-solid growth and characterization of aluminum nitride nanocones. J. Am. Chem. Soc. 127(4), 1318 (2005).

33. M. Radwan and M. Bahgat: A modified direct nitridation method for formation of nano-AlN whiskers. J. Mater. Proc. Technol. 181, 1 (2007).

34. H.A. Wriedt: The Al-N (aluminum-nitrogen) system. Bull. Alloys Phase Diagrams 7, 4 (1986).

35. M.F. Ashby, H. Shercliff, and D. Cebon: Materials: Engineering, Science, Processing and Design (Butterworth-Heinemann, Oxford, 2013); p. 51.

36. R.J. Stevens, A.N. Smith, and P.M. Norris: Measurement of thermal boundary conductance of a series of metal-dielectric interfaces by the transient thermoreflectance technique. J. Heat Transfer 127, 3 (2005).

\section{Supplementary Material}

To view supplementary material for this article, please visit https://doi.org/10.1557/jmr.2016.422. 